\title{
CLINICAL SCIENCE
}

\section{The effect of helicobacter pylori eradication on macrophage migration inhibitory factor, c-reactive protein and fetuin-a levels}

\author{
Levent Kebapcilar, ${ }^{1}$ Oktay Bilgir, ${ }^{1}$ Elif Cetinkaya, ${ }^{1}$ Murat Akyol, ${ }^{1}$ Ferda Bilgir, ${ }^{1}$ Giray Bozkaya ${ }^{2}$ \\ 1 Izmir Bozyaka Training and Research Hospital, Department of Internal Medicine - Izmir/Turkiye. 2 Izmir Bozyaka Training and Research Hospital, \\ Department of Biochemistry - Izmir/Turkiye.
}

OBJECTIVES: To determine the effect of Helicobacter pylori (H. pylori) eradication on blood levels of high-sensitivity C-reactive protein (hs-CRP), macrophage migration inhibitory factor and fetuin-A in patients with dyspepsia who are concurrently infected with $H$. pylori.

METHODS: H.pylori infection was diagnosed based on the ${ }^{14} \mathrm{C}$ urea breath test (UBT) and histology. Lansoprazole $30 \mathrm{mg}$ twice daily, amoxicillin $1 \mathrm{~g}$ twice daily, and clarithromycin $500 \mathrm{mg}$ twice daily were given to all infected patients for 14 days; ${ }^{14} \mathrm{C}$ UBT was then re-measured. In 30 subjects, migration inhibitory factor, fetuin-A and hs-CRP levels were examined before and after the eradication of $H$. pylori infection and compared to levels in 30 healthy subjects who tested negative for $H$. pylori infection.

RESULTS: Age and sex distribution were comparable between patients and controls. Migration inhibitory factor and hs-CRP levels were higher, and fetuin-A levels were lower, in $H$. pylori-infected patients $(p<0.05)$. Following eradication of $H$. pylori, migration inhibitory factor and hs-CRP levels were significantly decreased, whereas fetuin-A levels were increased. However, eradication of the organism did not change lipid levels $(p>0.05)$.

CONCLUSION: These findings suggest that $H$. pylori eradication reduces the levels of pro-inflammatory cytokines such as migration inhibitory factor and hs-CRP and also results in a significant increase in anti-inflammatory markers such as fetuin-A.

KEYWORDS: Helicobacter pylori; Eradication; Fetuin-A; Macrophage migration inhibitory factor; High-sensitivity C-reactive protein.

Kebapcilar L, Bilgir O, Cetinkaya E, Akyol M, Bilgir F, Bozkaya G. The effect of helicobacter pylori eradication on macrophage migration inhibitory factor, C-reactive protein and fetuin-a levels. Clinics. 2010;65(8):799-802.

Received for publication on April 12, 2010; First review publication on May 18, 2010; Accepted for publication on May 25, 2010

E-mail: leventkebapcilar@yahoo.com

Tel.: 0090 2223505050-4082

\section{INTRODUCTION}

Several epidemiologic studies have suggested associations between $H$. pylori seropositivity and atherosclerosis. ${ }^{1}$ Atherosclerosis is defined as a metabolic and inflammatory disease, and several inflammatory and immunologic factors have been established to significantly contribute to atherogenesis. Both humoral and cellular immune mechanisms play a major role in the onset and/or progression of atheromatous lesions. ${ }^{2}$ MIF is an important cytokine that regulates both adaptive and immune responses. ${ }^{3}$ It is a potent pro-inflammatory cytokine that has been reported to stimulate TNF and IL-6 expression ${ }^{4}$ and an important downstream marker of inflammation. C-reactive protein

Copyright (c) 2010 CLINICS - This is an Open Access article distributed under the terms of the Creative Commons Attribution Non-Commercial License (http:// creativecommons.org/licenses/by-nc/3.0/) which permits unrestricted noncommercial use, distribution, and reproduction in any medium, provided the original work is properly cited.
$(\mathrm{CRP})$ is one of the acute phase proteins that increase during systemic inflammation. 5,6 It has also been reported that measurement of serum levels of CRP using a highsensitivity assay (hs-CRP) can reveal subclinical inflammatory states that may reflect vascular inflammation. ${ }^{7}$

Anti-inflammatory cytokines produced during inflammation tend to modulate the inflammatory reaction. One cytokine, fetuin-A, is considered to be a potent antiinflammatory cytokine. Fetuin-A is an anti-inflammatory mediator that participates in macrophage deactivation, 8 anti-fibrotic activity, ${ }^{9}$ and inhibition of apoptosis in vascular smooth muscle cells. ${ }^{10}$

Although anti-inflammatory markers appear to have beneficial effects and decrease the risk of cardiovascular events, little is known about the effect of $H$. pylori eradication on inflammatory and anti-inflammatory markers of atherosclerosis. In this study, we determined the effect of H. pylori eradication on blood levels of MIF and fetuin-A in patients with dyspepsia in comparison to the levels in noninfected healthy subjects. 


\section{METHODS}

\section{Participants}

Subjects with dyspepsia symptoms who visited an internal medicine outpatient clinic were included in the study. Subjects with hypertension (HTN), diabetes mellitus (DM), known coronary artery disease, coagulation abnormalities, cerebrovascular disease, renal disease, rheumatoid arthritis, cancer, systemic or local infection, prior history of gastric surgery, smoking, and pregnant or lactating women were excluded. In addition, patients were excluded if they had used supplemental vitamins, statins, warfarin, antibiotics, nonsteroidal antiinflammatory drugs (NSAIDs), bismuth salts, or H2-receptor blockers and proton-pump inhibitors within 4 weeks prior to the study.

$H$. pylori was considered to be present when the ${ }^{14} \mathrm{C}$ urea breath test $\left({ }^{14} \mathrm{C}\right.$ UBT) and histological examination were positive. There were initially 62 patients with dyspeptic symptoms included in the study. After the administration of ${ }^{14} \mathrm{C}$ UBT, 11 subjects negative for $H$. pylori were excluded. The remaining 51 patients underwent endoscopy, and 5 of these subjects were excluded due to negative histology. Triple eradication therapy was given for 14 days to the remaining 46 patients positive both for ${ }^{14} \mathrm{C}$ UBT and histology. An additional 16 subjects were excluded from the study due to positive results on the repeated ${ }^{14} \mathrm{C}$ UBT. Thus, H. pylori infection was successfully eradicated in 30 subjects. MIF, fetuin-A, and hs-CRP levels were studied before and after the treatment and compared to levels in 30 healthy $H$. pylori-negative subjects who presented for only a routine check-up and had no other complaints, known chronic disease, or known medication use. The control subjects were considered to be $H$. pylori-negative if a rapid urease test was negative. This study was carried out between July 2008 and September 2009. Written informed consent was obtained from each subject, and research protocols were approved by the Ethical Committee of our institution.

\section{${ }^{14} \mathrm{C}$ urea breath test}

After fasting overnight, patients swallowed $37 \mathrm{kBq}(1 \mu \mathrm{Ci})$ of an encapsulated form of ${ }^{14} \mathrm{C}$-urea/citric acid composition (Helicap ${ }^{\mathrm{TM}}$ Noster System, Stockholm, Sweden) in $25 \mathrm{ml}$ water. Breath samples were collected with a special dry cartridge system (Heliprobe ${ }^{\mathrm{TM}}$ BreathCard $^{\mathrm{TM}}$; Noster System) after $10 \mathrm{~min}$. Patients exhaled gently into the cartridge mouthpiece until the indicator membrane changed color from orange to yellow. The BreathCard was inserted into a special small desktop Geiger-Müller counter (Heliprobe $^{\mathrm{TM}}$ Analyzer; Noster System) and activity was counted for $250 \mathrm{~s}$. Results were expressed both as counts per min (cpm) and as a grade (0: not infected and $<25 \mathrm{cpm} ; 1$ : equivocal and 25-50 cpm; 2 : infected and $>50 \mathrm{cpm}$ ) as suggested by the manufacturer and according to the counts obtained from the cartridges.

Endoscopy and histology. After fasting overnight, esophago-gastro-duodenoscopy was performed with an Olympus videoscope. Two biopsy specimens were obtained from the corpus and the antrum of the stomach. Biopsies were processed separately for histological examination according to a standard procedure, and hematoxylin and eosin staining and Giemsa staining were performed on these samples. A pathologist examined samples for active and chronic $H$. pylori infection.
Eradication regimen. Lansoprazole $30 \mathrm{mg}$ twice daily, amoxicillin $1 \mathrm{~g}$ twice daily, and clarithromycin $500 \mathrm{mg}$ twice daily were given for 14 days to all infected patients.

Laboratory Evaluation. Following an overnight fasting, venous blood samples were collected in the morning (8:009:00 A.M) for laboratory measurements. Blood samples for the measurement of fetuin-A, hs-CRP and MIF were evaluated in patients before and after eradication. Serum samples were stored at $-70{ }^{\circ} \mathrm{C}$ until analysis. Serum hs-CRP was determined using a commercially available sandwich ELISA kit (DRG International, USA) and serum MIF levels were measured with a quantitative sandwich human MIF ELISA (R\&D Systems, USA) using a monoclonal antibody against MIF. Serum concentrations of fetuin-A were measured using a human fetuin-A ELISA kit (BioVendor Laboratory Medicine Inc., Brno, Czech Republic). Total Cholesterol, Tg, HDL, LDL, glucose levels were determined using routine laboratory techniques.

\section{Statistical analysis}

The results are presented as means \pm SD. The Kolmogorov-Smirnov test was used to determine whether continuous variables were normally distributed. According to the KS test, all variables including age, BMI, lipid parameters, and concentrations of hs-CRP, fetuin-A and MIF showed a normal distribution. Student's t-test was used for the comparison of continuous variables. Differences between categorical variables were analyzed by Fisher's exact test. A paired sample t-test was used for the comparison of treatment effects on variables. The statistical analysis was carried out using Statistical Package for Social Sciences (SPSS), version 13.0 (SPSS Inc., Chicago, IL). A p-value of $<0.05$ was considered to be statistically significant.

\section{RESULTS}

The study group consisted of $30 \mathrm{H}$. pylori-infected patients $\left(29.1 \pm 7.5\right.$ years, $\left.23.0 \pm 4.5 \mathrm{~kg} / \mathrm{m}^{2}\right)$ and 30 control subjects $\left(29.1 \pm 5.8\right.$ years, $\left.23.7 \pm 3.1 \mathrm{~kg} / \mathrm{m}^{2}\right)$. When compared to controls, $H$. pylori-infected patients had significantly higher concentrations of hs-CRP $(0.90 \pm 0.88$ vs. $0.52 \pm 0.27 \mathrm{mg} / \mathrm{L}$, $P=0.028)$ and MIF $(8.5 \pm 2.4$ vs $5.1 \pm 1.5 \mathrm{ng} / \mathrm{mL}, P<0.001)$ as well as significantly lower fetuin-A levels $(28.7 \pm 7.7$ vs $50.1 \pm 20.9 \mathrm{ng} / \mathrm{mL}, P<0.001)$. No statistically significant difference was observed for BMI, lipid levels, fasting glucose levels, and age between $H$. pylori-infected patients and healthy controls (Table 1). Following eradication of H. pylori, MIF and hs-CRP concentrations decreased significantly $(8.5 \pm 2.4$ vs $6.5 \pm 1.8 \mathrm{ng} / \mathrm{mL}, P<0.001$ and $0.90 \pm 0.88$ vs. $0.63 \pm 0.55 \mathrm{mg} / \mathrm{L}, P=0.004$, respectively) However, the lipid levels and BMI were not different following eradication $(\mathrm{P}>0.05)$. H. pylori eradication was associated with a progressive increase in serum fetuin-A levels (28.7 \pm 7.7 vs $36.8 \pm 16.9 \mathrm{ng} / \mathrm{mL}, P=0.007)$. Pearson's correlation analysis showed that prior to eradication, MIF levels were significantly and negatively correlated with those of fetuin-A (Fig 1: $r=-0.4, \mathrm{P}=0.002$ ).

\section{DISCUSSION}

In this study, we found that MIF and hs-CRP levels were significantly increased and fetuin-A levels were significantly decreased in $H$. pylori-infected patients when compared to control subjects. Eradication of $H$. pylori was 


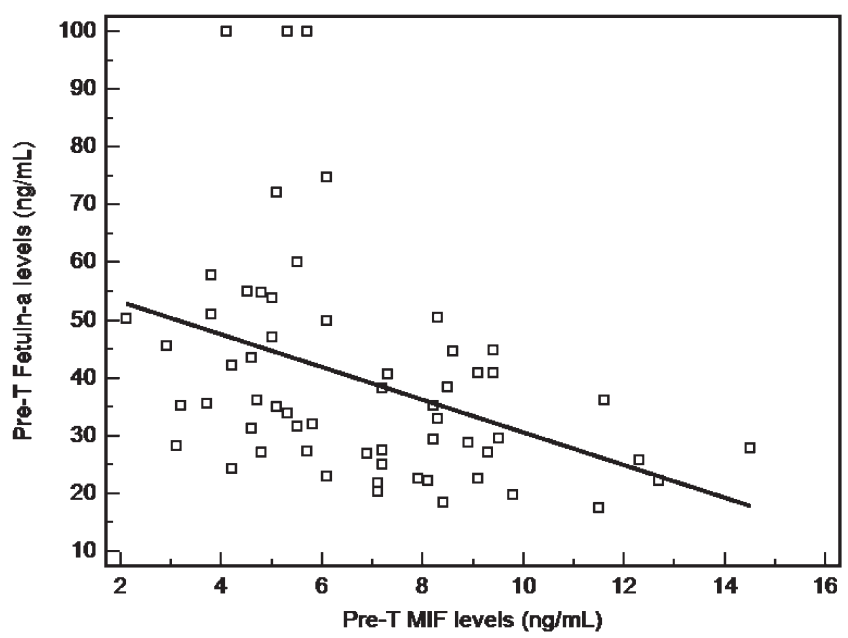

Figure 1 - Pearson's correlation analysis showed that levels of MIF were significantly and negatively correlated with those of fetuin$A(r=-0.4, P=0.002)$.

significantly associated with increased levels of fetuin-A and reduced levels of MIF and hs-CRP in patients free of classic cardiovascular (CV) risk factors. However, eradication of the microorganism had no effect on the lipid profile.

Inflammation is a common feature of all stages of atherosclerosis. However, conflicting results regarding the relationship between $H$. pylori infection and atherosclerosis have been reported. Although various studies have investigated the potential correlation between $H$. pylori infection and ischemic heart disease (IHD), several epidemiological studies have not shown any clear correlation between H. pylori infection and IHD.

Table 1 - Clinical and laboratory characteristics of patients with $H$. pylori vs. control subjects. Results are presented as means $\pm S D$.

\begin{tabular}{lccc}
\hline & H. pylori $(\mathrm{n}=\mathbf{3 0})$ & Control $(\mathrm{n}=\mathbf{3 0})$ & P value \\
\hline BMI $\left(\mathrm{kg} / \mathrm{m}^{2}\right)$ & $22.9 \pm 4.5$ & $23.7 \pm 3.1$ & 0.4 \\
Age $(\mathrm{yr})$ & $29.1 \pm 7.5$ & $29.1 \pm 5.8$ & 0.9 \\
Glucose $(\mathrm{mg} / \mathrm{dL})$ & $87 \pm 8.5$ & $86.3 \pm 9.4$ & 0.7 \\
TC $(\mathrm{mg} / \mathrm{dL})$ & $180.2 \pm 31.3$ & $188.3 \pm 38.6$ & 0.4 \\
Tg (mg/dL) & $80.2 \pm 30.2$ & $95.2 \pm 35.2$ & 0.1 \\
HDL-C $(\mathrm{mg} / \mathrm{dL})$ & $56.8 \pm 13.5$ & $51.5 \pm 9.5$ & 0.1 \\
LDL-C $(\mathrm{mg} / \mathrm{dL})$ & $111.7 \pm 33.1$ & $105.5 \pm 33.0$ & 0.4 \\
hs-CRP $(\mathrm{mg} / \mathrm{L})$ & $0.90 \pm 0.88$ & $0.52 \pm 0.27$ & 0.028 \\
Fetuin-a $(\mathrm{ng} / \mathrm{mL})$ & $28.7 \pm 7.7$ & $50.1 \pm 20.9$ & $<0.001$ \\
MIF $(\mathrm{ng} / \mathrm{mL})$ & $8.5 \pm 2.4$ & $5.1 \pm 1.5$ & $<0.001$ \\
\hline
\end{tabular}

Table 2 - Clinical and laboratory characteristics of patients before and after $H$. pylori eradication. Results are presented as mean \pm SD.

\begin{tabular}{lccc}
\hline & Before eradication & After eradication & P-value \\
\hline BMI $\left(\mathrm{kg} / \mathrm{m}^{2}\right)$ & $22.9 \pm 4.5$ & $22.6 \pm 5.2$ & 0.1 \\
$\mathrm{TC}(\mathrm{mg} / \mathrm{dL})$ & $180.2 \pm 31.3$ & $172.8 \pm 38.5$ & 0.1 \\
Tg $(\mathrm{mg} / \mathrm{dL})$ & $80.2 \pm 30.2$ & $92.6 \pm 49.6$ & 0.2 \\
HDL-C $(\mathrm{mg} / \mathrm{dL})$ & $56.8 \pm 13.5$ & $54.6 \pm 12.2$ & 0.6 \\
LDL-C $(\mathrm{mg} / \mathrm{dL})$ & $111.7 \pm 33.1$ & $104.5 \pm 31.2$ & 0.1 \\
hs-CRP $(\mathrm{mg} / \mathrm{L})$ & $0.90 \pm 0.88$ & $0.63 \pm 0.55$ & 0.004 \\
Fetuin-a $(\mathrm{ng} / \mathrm{mL})$ & $28.7 \pm 7.7$ & $36.8 \pm 16.9$ & 0.007 \\
MIF $(\mathrm{ng} / \mathrm{mL})$ & $8.5 \pm 2.4$ & $6.5 \pm 1.8$ & $<0.001$ \\
\hline
\end{tabular}

Recent studies have focused on the effect of $H$. pylori infection on hs-CRP levels. ${ }^{11,12}$ In recent studies, serum levels of hs-CRP were higher in $H$. pylori-infected patients than in non-infected healthy control groups. It was previously demonstrated that serum levels of hs-CRP were significantly reduced in most $H$. pylori-infected patients after successful eradication of $H$. pylori. ${ }^{13}$ These findings are in agreement with the results of our study, which showed that hs-CRP production was significantly reduced after eradication of $H$. pylori, implying a beneficial effect in decreasing systemic inflammation.

MIF levels were higher in $H$. pylori-infected patients than in healthy controls. Recently, two reports showed that MIF production was increased during $H$. pylori infection. ${ }^{14,15}$ However, to our knowledge, no report in the literature has examined the effect of treatment on MIF levels in H. pyloriinfected patients. In this study, we demonstrated that the eradication of the offending microorganism was associated with significantly decreased MIF levels. MIF is a key proinflammatory mediator that plays a pivotal role in inflammatory and immune diseases. It has been demonstrated that MIF increases inflammatory responses including the levels of cytokines such as IL-1, IL-6, IL-8, and TNF$\alpha$; it also increases proliferative responses in many cell types by inducing the NF- $\kappa \mathrm{B}$, Erk1/2, and AP-1 signaling pathways $^{16-18}$, which have been associated with gastric cancer, intestinal cancer ${ }^{19,20}$, and atherosclerosis. ${ }^{21,22}$ MIF functions via various mechanisms: leukocyte recruitment and arrest via its chemokine-like functions, macrophage activation and production of proinflammatory cytokines, foam cell formation, and processes of cell proliferation and anti-apoptosis. ${ }^{23}$ MIF inhibition has been shown to induce the stabilization and even regression of atherosclerotic plaques. ${ }^{22}$ Based on these observations, $H$. pylori eradication may exert a beneficial effect by decreasing the MIF upregulation that occurs in this infection.

In contrast, fetuin- $\mathrm{A}$ is an anti-inflammatory mediator that participates in macrophage deactivation. Specifically, fetuin-A enhances the cellular uptake of cationic inhibitors of pro-inflammatory cytokine synthesis by macrophages, thus preventing the morbid sequelae of infection that result from overproduction of pro-inflammatory cytokines. ${ }^{24-26}$ Accumulating evidence shows that low fetuin-A concentrations are related to increased cardiovascular mortality. ${ }^{27-29}$ To our knowledge, there is no report in the literature about fetuin-A levels and the effect of treatment in $H$. pyloriinfected patients. Serum fetuin-A levels decrease with H. pylori infection and our investigation showed that eradication of the offending microorganism was associated with significantly increased fetuin-A levels.

This study demonstrates beneficial effects of $H$. pylori eradication on markers of low-grade inflammation, i.e., decreased MIF and hs-CRP levels and increased fetuin-A levels, in patients free of cardiovascular risk factors. There is a need for large interventional randomized studies to prove an association between Helicobacter pylori seropositivity and atherosclerosis.

\section{REFERENCES}

1. Danesh J, Collins R, Peto R. Chronic infections and coronary heart disease: is there a link? Lancet. 1997;350:430-6, doi: 10.1016/S01406736(97)03079-1.

2. Hansson GK. Inflammation, atherosclerosis, and coronary artery disease. N Engl J Med. 2005;352:1685-95, doi: 10.1056/NEJMra043430. 
3. Calandra T, Roger T. Macrophage migration inhibitory factor: a regulator of innate immunity. Nat Rev Immunol. 2003;3:791-800, doi: 10.1038/ nri1200.

4. Pakozdi A, Amin MA, Haas CS, Martinez RJ, Haines GK, 3rd, Santos LL, et al. Macrophage migration inhibitory factor: a mediator of matrix metalloproteinase-2 production in rheumatoid arthritis. Arthritis Res Ther. 2006;8:R132, doi: 10.1186/ar2021.

5. Libby P, Ridker PM. Inflammation and atherosclerosis: role of C-reactive protein in risk assessment. Am J Med. 2004;116(Suppl 6A):9S-16S, doi: 10.1016/j.amjmed.2004.02.006

6. Blake GJ, Ridker PM. C-reactive protein: a surrogate risk marker or mediator of atherothrombosis? Am J Physaiol. 2003;285:R1250-R1252.

7. Wilson AM, Ryan MC, Boyle AJ. The novel role of C-reactive protein in cardiovascular disease: risk marker or pathogen. Int J Cardiol. 2006;106:291-7, doi: 10.1016/j.ijcard.2005.01.068.

8. Wang H, Zhang M, Bianchi M, Sherry B, Sama A, Tracey KJ. Fetuin (alpha2 - HS -glycoprotein) opsonizes cationic macrophage deactivating molecules. Proc Natl Acad Sci USA 1998;95:14429-34, doi: 10.1073/pnas. 95.24.14429.

9. Demetriou M, Binkert C, Sukhu B, Tenenbaum HC, Dennis JW. Fetuin/ alpha2-HS glycoprotein is a transforming growth factor-beta type II receptor mimic and cytokine antagonist. J Biol Chem. 1996;271:12755-61, doi: $10.1074 /$ jbc.271.22.12755.

10. Reynolds JL, Skepper JN, McNair R, Kasama T, Gupta K, Weissberg PL, et al. Multifunctional roles for serum protein fetuin-A in inhibition of human vascular smooth muscle cell calcification. J Am Soc Nephrol. 2005;16:2920-30, doi: 10.1681/ASN.2004100895.

11. Jafarzadeh A, Hassanshahi GH, Nemati M. Serum Levels of HighSensitivity C-Reactive Protein (hs-CRP) in Helicobacter pylori-Infected Peptic Ulcer Patients and Its Association with Bacterial CagA Virulence Factor. Dig Dis Sci. 2009 Jan 22. [Epub ahead of print]

12. Stettin D, Waldmann A, Ströhle A, Hahn A. Association between Helicobacter pylori-infection, C-reactive protein and status of B vitamins. Adv Med Sci. 2008;53:205-13, doi: 10.2478/v10039-008-0050-8.

13. Kanbay M, Gür G, Yücel M, Yilmaz U, Boyacioğlu S. Does eradication of Helicobacter pylori infection help normalize serum lipid and CRP levels? Dig Dis Sci. 2005;50:1228-31, doi: 10.1007/s10620-005-2764-9.

14. Beswick EJ, Pinchuk IV, Suarez G, Sierra JC, Reyes VE. Helicobacter pylori CagA-dependent macrophage migration inhibitory factor produced by gastric epithelial cells binds to CD74 and stimulates procarcinogenic events. J Immunol. 2006;176:6794-0801.

15. Xia HH, Lam SK, Chan AO, Lin MC, Kung HF, Ogura K, et al. Macrophage migration inhibitory factor stimulated by Helicobacter pylori increases proliferation of gastric epithelial cells. World J Gastroenterol. 2005;11:1946-50.

16. IshiguroYT, Ohkawara H, Sakuraba K, Yamagata H, Hiraga S, Yamaguchi S, et al. Macrophage migration inhibitory factor has a proinflammatory activity via the p38 pathway in glucocorticoid-resistant ulcerative colitis. Clin. Immunol. 2006; 120335-341.
17. Mitchell RA, Liao J H, Chesney G, Fingerle-Rowson J, Baugh JD, Bucala R. Macrophage migration inhibitory factor (MIF) sustains macrophage proinflammatory function by inhibiting p53: regulatory role in the innate immune response. Proc. Natl. Acad. Sci. 2002; USA 99345-350.

18. Ren Y, Chan HM, Li Z, Lin C, Nicholls J, Chen CF, et al. Upregulation of macrophage migration inhibitory factor contributes to induced N-Myc expression by the activation of ERK signaling pathway and increased expression of interleukin-8 and VEGF in neuroblastoma. Oncogene. 2004; 23:4146-54, doi: 10.1038/sj.onc. 1207490.

19. Beswick EJ, Reyes VE. CD74 in antigen presentation, inflammation, and cancers of the gastrointestinal tract. World J Gastroenterol. 2009;15:285561, doi: 10.3748/wig.15.2855.

20. Bucala R, Donelly SC. Macrophage migration inhibitory factor: a probable link between inflammation and cancer. Immunity. 2007; 26:281-5, doi: 10. 1016/j.immuni.2007.03.005.

21. Burger-Kentischer A, Goebel H, Seiler R, Fraedrich G, Schaefer HE, Dimmeler S, et al. Expression of macrophage migration inhibitory factor in different stages of human atherosclerosis. Circulation. 2002;105:15616, doi: 10.1161/01.CIR.0000012942.49244.82.

22. Bernhagen J, Krohn R, Lue H, Gregory JL, Zernecke A, Koenen RR, et al. MIF is a noncognate ligand of CXC chemokine receptors in inflammatory and atherogenic cell recruitment. Nat Med. 2007;13:587-96, doi: 10.1038/ nm1567.

23. Zernecke A, Shagdarsuren E, Weber C. Chemokines in atherosclerosis: an update. Arterioscler Thromb Vasc Biol. 2008;28:1897-908, doi: 10 1161/ATVBAHA.107.161174.

24. Wang H, Zhang M, Soda K, Sama A, Tracey KJ. Fetuin protects the fetus from TNF. Lancet. 1997;350:861-2, doi: 10.1016/S0140-6736(05)62030-2.

25. Lord JM. A physiological role for alpha2-HS glycoprotein: stimulation of macrophage uptake of apoptotic cells. Clin Sci (Lond). 2003;105:267-8, doi: $10.1042 /$ CS20030177.

26. Ombrellino $M$, Wang $H$, Yang $H$, Zhang $M$, Vishnubhakat J, Frazier A, et al. Fetuin, a negative acute phase protein, attenuates TNF synthesis and the innate inflammatory response to carrageenan. Shock.2001;15;181-5, doi: 10.1097/00024382-200115030-00004.

27. Ketteler M, Bongartz P, Westenfeld R, Wildberger JE, Mahnken AH, Bohm R, et al. Association of low fetuin-A (AHSG) concentrations in serum with cardiovascular mortality in patients on dialysis: a crosssectional study. Lancet. 2003;361:827-33, doi: 10.1016/S01406736(03)12710-9.

28. Stenvinkel P, Wang K, Qureshi AR, Axelsson J, Pecoits-Filho R, Gao P, et al. Low fetuin-A levels are associated with cardiovascular death: impact of variations in the gene encoding fetuin. Kidney Int. 2005;67:2383-92, doi: 10.1111/j.1523-1755.2005.00345.x.

29. Koos R, Brandenburg V, Mahnken AH, Mühlenbruch G, Stanzel S, Günther RW, et al. Association of fetuin-A levels with the progression of aortic valve calcification in non-dialyzed patients. Eur Heart J. 2009;30:2054-61, doi: 10.1093/eurheartj/ehp158. 